\title{
Low-Cost I-V Tracer for PV Modules under Real Operating Conditions
}

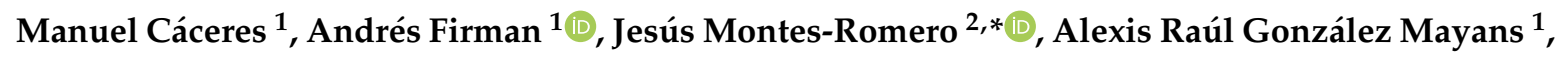 \\ Luis Horacio Vera ${ }^{1}$, Eduardo F. Fernández ${ }^{2}$ and Juan de la Casa Higueras ${ }^{2}$ (I) \\ 1 Group of Renewable Energies (GER), Northeastern National University, Corrientes 3400, Argentina; \\ drmanu.caceres@gmail.com (M.C.); andresfirman@gmail.com (A.F.); \\ raulgonzalezmayans@gmail.com (A.R.G.M.); luis.horacio.vera@comunidad.unne.edu.ar (L.H.V.) \\ 2 IDEA Solar Energy Research Group, Electronics and Automation Engineering Department, University of \\ Jaén, Las Lagunillas Campus, 23071 Jaén, Spain; eduardo.fernandez@ujaen.es (E.F.F.); \\ delacasa@ujaen.es (J.d.l.C.H.) \\ * Correspondence: jmontes@ujaen.es; Tel.: +34-953-21-3306
}

Received: 5 June 2020; Accepted: 14 August 2020; Published: 20 August 2020

check for updates

\begin{abstract}
Solar photovoltaic technologies have undergone significant scientific development. To ensure the transfer of knowledge through the training of qualified personnel, didactic tools that can be acquired or built at a reasonable price are needed. Most training and research centres have restrictions on acquiring specific equipment due to its high cost. With this in mind, this article presents the development and transfer of a low-cost I-V curve tracer acquisition system. The device is mAde up of embedded systems with all the necessary hardware and software for its operation. The hardware and software presented are open source and have a low cost, i.e., the estimated mAterial cost of the system is less than 200 euros. For its development, four institutions from three different countries participated in the project. Three photovoltaic technologies were used to measure the uncertainties related to the equipment developed. In addition, the system can be transferred for use as an academic or research tool, as long as the measurement does not need to be certified. Two accredited laboratories have certified the low uncertainties in the measurement of the proposed system.
\end{abstract}

Keywords: current-voltage characteristics; photovoltaic systems; I-V curve tracer; outdoor characterisation

\section{Introduction}

Renewable energies have experienced significant growth during the last decade. Furthermore, from a technological point of view, the development of more efficient and sustainable systems has been achieved [1-3]. In this context, electrical energy production through the photovoltaic (PV) conversion of the incoming sunlight represents an important alternative due to its inherent characteristics. Compared to other energy generation systems, the large number of applications and high reliability can be highlighted as some of the most outstanding features of PV $[4,5]$. Therefore, systematic studies are required in order to determine and explain the operation principles of different related technologies $[6,7]$, both existing or in development. This is relevant for mAximising the operational efficiency and to elaborate upon methods used to exploit the electric energy produced [8].

The I-V curve of a PV cell, module or array under determined operating conditions provides information related to its electrical behaviour (normal or anomalous) and about its energy generation capacity [9]. It is the most important and widely used metric to describe the electrical output of a PV device [10-12].

PV modules and arrays are built using a series or parallel connection of several cells. In normal operating conditions, the I-V curve has a similar shape regardless of the cell interconnection. The 
normalized I-V curve of a PV device is shown in Figure 1 . The I-V curve of a PV device is described by a set of parameters, such as the short-circuit current (Isc), the open-circuit voltage (Voc) and the mAximum power point $(\mathrm{Pm})$, which is defined by the voltage and current at the mAximum power point $(\mathrm{Vm}$ and Im).

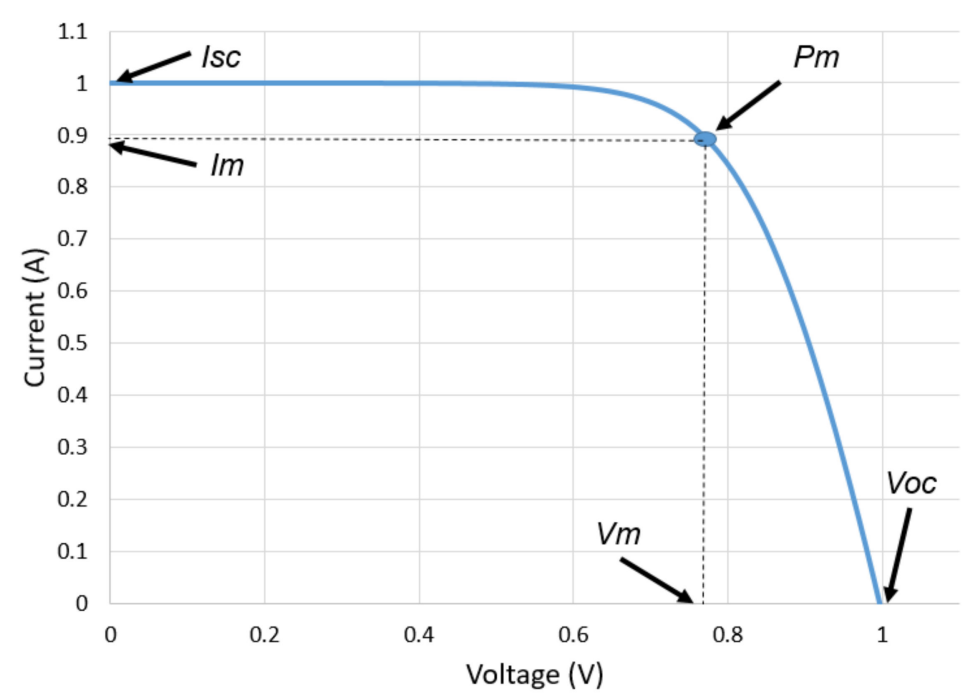

Figure 1. Normalized I-V curve of a photovoltaic device.

Those parameters depend on the size of the PV generator and the operating conditions, usually the irradiance and temperature [13]. The variations of these parameters can be described and represented by using multiple mAthematical models [14-17]. The data needed to use those methods can be experimentally obtained from the I-V curve of the technology under investigation. This reinforces the need for I-V tracers for studying and improving the knowledge of PV technology [18,19].

Photovoltaic technology is a mAjor research field; the transfer of knowledge from the different findings to society is one of the most relevant challenges of this field. This transfer can be accomplished through the training of qualified human resources in academic environments. However, most of these training centres have significant access restrictions to the equipment required for the testing, evaluation and diagnosis of PV devices. In general, only specialised centres can afford the high cost of the equipment. Consequently, the development of tools to fulfil the educational and scientific objectives is necessary. This is fundamental to transfer the knowledge at an affordable cost, and therefore, to mAke it possible. The design, implementation and transference of the equipment for the characterisation of photovoltaic devices must be accomplished to ensure the development of this technology [20].

Nowadays, mAny I-V tracers can be found on the mArket. However, they are mAinly focused on the fault detection and performance evaluation of PV plants [21]. Due to its high cost, the acquisition of this equipment is limited to specific centres. Several studies have been carried out to improve the different methodologies of the I-V tracing methods [22-27]. Nevertheless, a complete and detailed framework of all the components required to implement the I-V tracer is rarely offered in the literature.

In recent work, we proposed a complete framework to build an I-V curve tracer [28]. This early system was based on three principles: (1) the use of general-purpose instrumentation to perform all the measurements, which ensures accuracy and precision due to the measurement certificate from the mAnufacturer; (2) the use of open-hardware platforms, which allows for the reproduction of the system in any laboratory; and (3) scalability to measure any PV device. This framework reduced the system to the minimum necessary commercial elements. Nevertheless, commercial general-purpose instrumentation can be considered high-cost equipment. In this context, and as a contribution to the exposed problem, the present article proposes the development of a low-cost I-V curve tracer system that does not use any commercial instrument. It is based on open-hardware platforms and electronic designs. The low-cost characteristic allows for greater accessibility by any centre. Even if the 
proposed equipment does not have an individual measurement certificate, extensive validation of the measurement accuracy has been carried out. The dissemination of this equipment is expected to have a positive impact on the scientific-academic community working in the PV sector. All the necessary electronic designs to build the device are included in detail in order to be easily replicated.

The paper is organised as follows: First, the operating principles of all the components of the system are provided in detail (Section 2). Second, the methodology used to validate the prototype is presented (Section 3). Then, the obtained results of this validation are given (Section 4). Finally, the mAin conclusions are presented (Section 5).

\section{Operating Principle of the Developed System}

In this section, a general description of the mAin components of the system is presented. This includes details in the signal-conditioning circuits. It provides the calibration performed to develop and validate the presented prototype. In addition, a simplified budget of the components needed to replicate the system is provided.

\subsection{System Description}

The proposed system performs the measurement, acquisition, sweep and analysis of the voltage and current values of a PV module under real operating conditions. The sweeping process is based on a capacitive load [29], as one among mAny possible methods [21,30]. Connecting the PV module to a capacitor with a small negative residual charge and exposing the PV module to solar radiation controls the working point sweep. This configuration causes a current to pass through the capacitor, where this current varies from the short-circuit current at the initial moment to zero when the capacitor voltage reaches the open-circuit voltage. During the transient period, the system measures the voltage and current. The system sampling rate allows for accurate measurement of the I-V curve in outdoor operating conditions.

In Figure 2, the electrical diagram of the I-V sweeping circuit is presented. Switch S1 controls the negative pre-charge of the capacitor. This process must be done before connecting the PV module to the capacitor in order to obtain the Isc point during the charging process. Switch S2 connects the capacitor to the PV module. Finally, switch S3 performs the discharge of the capacitor, dissipating the stored energy on a power resistor $\mathrm{Rd}$ after the charging process is complete.

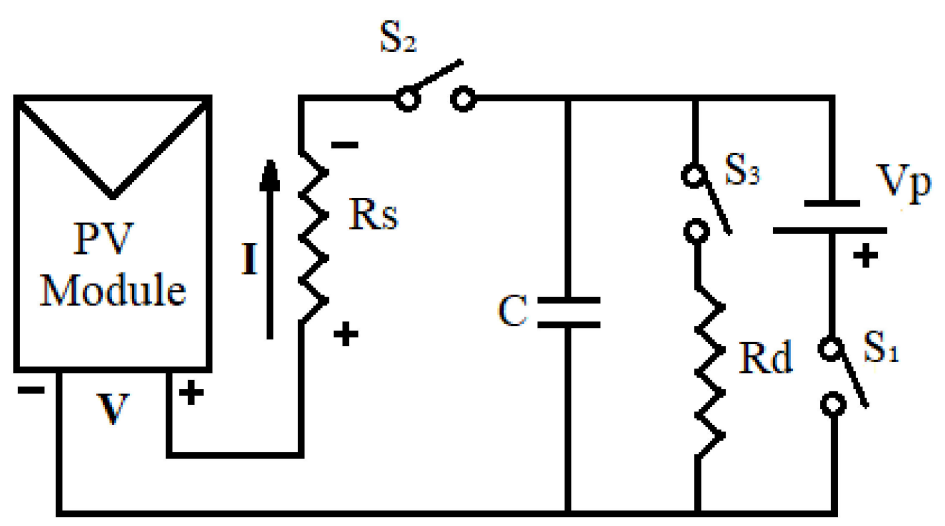

Figure 2. Electrical diagram of the proposed I-V curve tracer.

A key aspect of the design and customisation of the equipment by the end-user is the determination of the capacitor. The characteristics of this component will depend on the PV module being tested and the irradiance and temperature conditions during the experiment. In order to be suitable, the obtained curves have to fulfil the requirements proposed in Duran et al. [31]: at least 50 points per curve acquired between $20 \mathrm{~ms}$ and $100 \mathrm{~ms}$. As later discussed, the proposed system has been designed for a fixed I-V curve acquisition time of approximately $100 \mathrm{~ms}$. 
The mAximum capacitor voltage range must be $20 \%$ greater than the Voc for safety reasons and must have low internal resistance. There is no single capacity value that offers a solution to the different types of commercial PV modules and irradiance range outdoors. Therefore, it must be calculated for each scenario. In Spertino et al. [29], after extensive analysis and experimental work, the capacity $C$ is recommended to be calculated by using the following expression:

$$
C \simeq 0.55 t \frac{I s c}{V o c}
$$

where $t$ is the capacitor charging time, which should be higher than $20 \mathrm{~ms}$ for Isc and Voc conditions close to standard test conditions (STC). In this way, the irradiances range that can be obtained from a particular PV module with the same capacity value is mAximized. For quick modifications of the hardware system, the end-user should evaluate the possibility of connecting the capacitor to the prototype using external connectors.

A shunt resistor ( 0.5 class $15 \mathrm{~A} / 150 \mathrm{mV})$ is used for the current measurements [32]. The system measures the voltage on the PV device terminals with a four-wire configuration in order to remove the voltage drop produced across wires and connectors.

The irradiance and cell temperature are the basic parameters used to define the operating conditions. In addition, the developed system includes the use of a reference cell [33]. It is composed of two polycrystalline silicon photovoltaic cells. One cell is an irradiance transducer operating at the Isc point with a shunt resistor and the other is used to measure the cell temperature operating at the Voc point. A resistance temperature detector (RTD) PT100 can also acquire the temperature [34].

Because of the requirements of this work, which involve the acquisition and processing of four signals, an analysis of low-cost embedded systems was carried out. In this sense, four systems with similar features were studied: PSoC 5LP (Infineon+Cypress, San José, CA, USA), NUCLEO-F411RE (STMicroelectronics, Plan-les-Ouates, Switzerland), LPCXpresso18 (NXP, Eindhoven, The Netherlands) and TivaC Series Launchpad (Texas Instruments Incorporated, Dallas, TX, USA). The mAin technical-economic characteristics of the considered systems are shown in Table 1. The TivaC Series LaunchPad is a low-cost embedded system, complies with the optimal features for analog signal acquisition, i.e., it has two independent analog to digital converters (ADC) of 12 bits and a mAximum sampling rate of $1 \mathrm{Ms} / \mathrm{s}$. The ADCs can operate within a temperature range of -40 to $+85^{\circ} \mathrm{C}$ with a nominal total error of \pm 10 LSB. In addition, they also provide an internal temperature sensor to determine whether the system is operating under non-recommended temperatures that could increase the uncertainty $[35,36]$.

Table 1. Technical-economic characteristics of four commercial embedded systems.

\begin{tabular}{ccccc}
\hline $\begin{array}{c}\text { Commercial } \\
\text { Embedded System }\end{array}$ & Cores and Memories & $\begin{array}{c}\text { Digital } \\
\text { Peripherals }\end{array}$ & $\begin{array}{c}\text { Analog } \\
\text { Peripherals }\end{array}$ & Price \\
\hline $\begin{array}{c}\text { CY8CKIT-059 PsoC } \\
\text { 5LP Prototyping } \\
\text { Kit }\end{array}$ & $\begin{array}{c}\text { ARM Cortex-M3 Flash: } 256 \mathrm{kB} \\
\text { SRAM: } 64 \text { kB EEPROM: } 2 \mathrm{kB}\end{array}$ & $\begin{array}{c}\text { universal digital } \\
\text { blocks }\end{array}$ & $\begin{array}{c}\text { 2 SAR } 12 \mathrm{bits} 1 \mathrm{kS} / \mathrm{s} ; \\
20 \mathrm{bits}\end{array}$ & $11.50 €$ \\
& & & $180 \mathrm{~S} / \mathrm{s}$ & $1 \mathrm{ADC}$ \\
NUCLEO-F411RE & ARM Cortex-M4 Flash: $256 \mathrm{kB}$ & $50 \mathrm{GPIO}$ & $12 \mathrm{bits}$ & $11.70 €$ \\
& SRAM: $128 \mathrm{kB}$ & & $2.4 \mathrm{MS} / \mathrm{s}$ & $24.30 €$ \\
LPCXpresso18S37 & ARM Cortex-M3 Flash: $1 \mathrm{MB}$ & 49 GPIO & $10 \mathrm{bits}$ & \\
& SRAM: $136 \mathrm{kB}$ EEPROM: $16 \mathrm{kB}$ & & $400 \mathrm{kS} / \mathrm{s}$ & $2 \mathrm{ADC}$ \\
Tiva C Series & ARM Cortex-M4 Flash: $256 \mathrm{kB}$ & $48 \mathrm{GPIO}$ & $12 \mathrm{bits}$ & $11.50 €$ \\
LaunchPad & SRAM: $32 \mathrm{kB}$ EEPROM: $2 \mathrm{kB}$ & & $1 \mathrm{MS} / \mathrm{s}$ & \\
\hline
\end{tabular}

ADC: Analog to digital converter, GPIO: General purpose input/output, SAR: Successive approximation register. 
Voltage signal transducers of different mAgnitudes and with a determined bandwidth measure the signals. For this reason, the conditioning and filtering stages must be included to suit the requirements of the A/D converters. An image of the developed boards is shown in Figure 3 . The bottom plate corresponds to the analog signal conditioning stages, the middle plate corresponds to the commercial board TIVA and the top plate corresponds to the power board that controls the capacitive load.

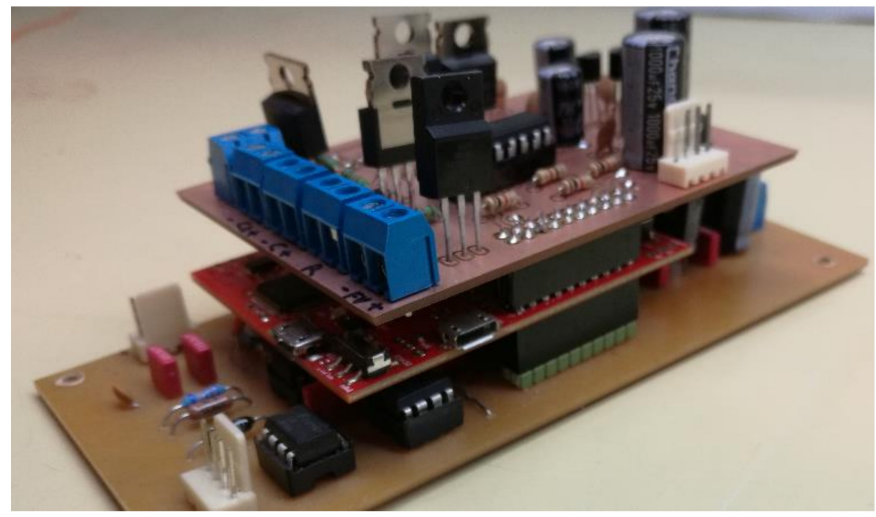

Figure 3. Last version of the prototype boards. The signal conditioning stage is at the bottom, the commercial embedded system board is in the middle and the power stage is at the top.

The measurement system was mAde for its use as a testing and characterisation instrument for academic environments. Hence, simple software was implemented to control the measurement system and performs the subsequent analysis of the acquired data. This software was developed on LabVIEW IDE (version 2019, National Instruments, Austin, TX, USA) due to its simplicity and intuitive characteristics. The mAin window of the developed software is shown in Figure 4.

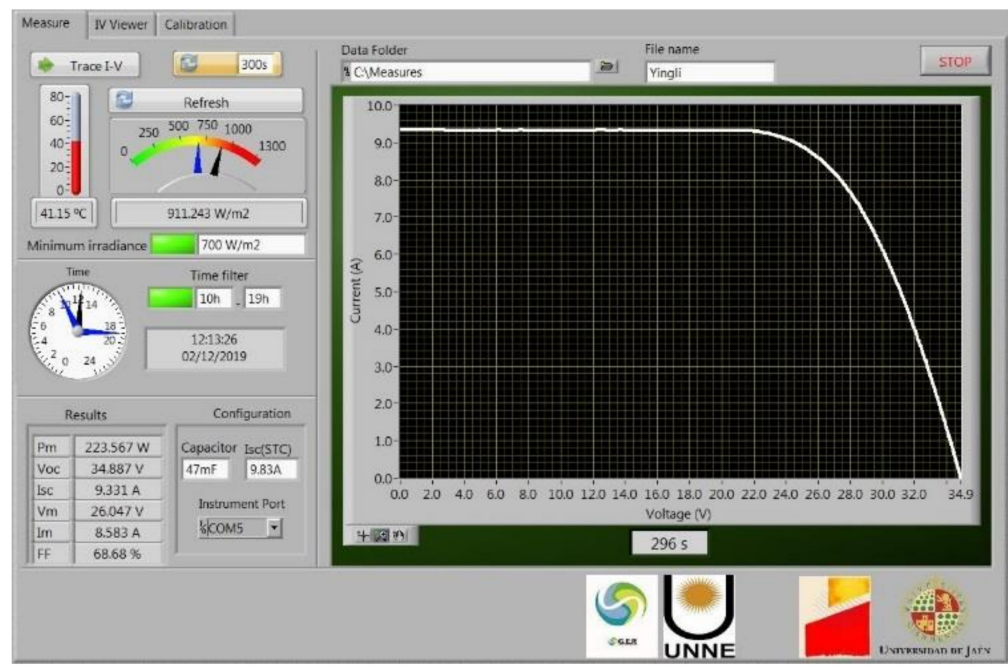

Figure 4. Main window of the developed control software. 


\subsection{Analog Signal Conditioning}

As previously explained, the system was designed to measure four variables, namely, PV module voltage and current, irradiance and temperature. The PV module voltage and current must be acquired simultaneously. The design of the amplification stages was carried out as a function of the transducers employed in the proposed system [37]. These variables are summarised in Table 2.

Table 2. Technical characteristics of the transducers used in the measurement of the variables.

\begin{tabular}{cccc}
\hline Channel & Measurement Range & Transducer & Transducer Operation Range \\
\hline $\begin{array}{c}\text { Photovoltaic (PV) } \\
\text { module current (I) }\end{array}$ & 0 to $12 \mathrm{~A}$ & Shunt Resistor Class 0.5 & 0 to $12 \mathrm{~A} / 120 \mathrm{mV}$ \\
PV module voltage (V) & 0 to $100 \mathrm{~V}$ & Attenuator & 0 to $2.1 \mathrm{~V}$ \\
Irradiance (G) & 0 to $1300 \mathrm{~W} / \mathrm{m}^{2}$ & $\begin{array}{c}\text { Class } 0.5 \text { shunt } \\
\text { connected poly-Si cell } \\
\text { Open-circuit poly-Si cell }\end{array}$ & $\begin{array}{c}0 \text { to } 3.5 \mathrm{~A} / 42 \mathrm{mV} \\
0.5 \text { to } 0.8 \mathrm{~V}\end{array}$ \\
Cell temperature (T) & 0 to $100^{\circ} \mathrm{C}$ & PT100 resistor & $\begin{array}{c}0.5 \mathrm{~V} \text { to } 0.7 \mathrm{~V} \text { (with a } 5 \mathrm{~mA} \\
\text { constant current source) }\end{array}$ \\
\hline
\end{tabular}

Based on the analog inputs, different signal conditioning stages were created in order to mAximize the measurement accuracy. In this sense, the amplification stages were developed for the current, irradiance and temperature channels. For the voltage channel, an attenuation stage with low impedance at the output was implemented. The instrumentation operational amplifier AD620BNZ by Analog Devices (Norwood, mA, USA) is used to perform the signals conditioning. The electrical schematic of the current and voltage stages is shown in Figures 5 and 6. The amplification stage for irradiance and temperature is similar to the current channel. The gain is adapted to the required values by the transducer. Therefore, any type of irradiance and temperature sensor can be used, as long as it fits the specifications of the channel. The symmetrical source stabilized at $\pm 12 \mathrm{~V}$ powers the stages.

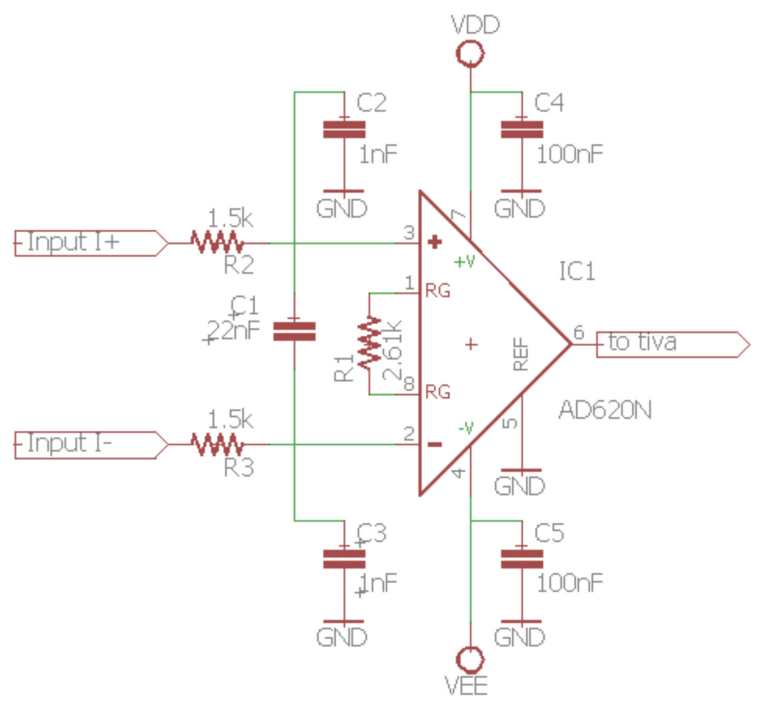

Figure 5. Amplification stage for the current measurement. 


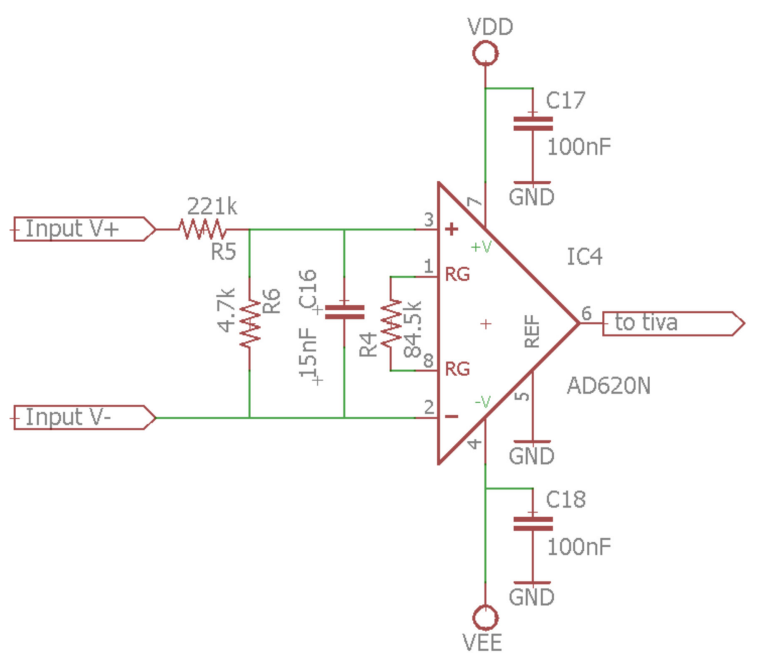

Figure 6. Attenuation stage for the voltage measurement.

Antialiasing filters limit the differential input bandwidths with a cut-off frequency of $2.36 \mathrm{kHz}$. This is key to simplifying the digital signal processing and avoiding erroneous results. The acquisition of 500 points in less than $100 \mathrm{~ms}$ at a $5 \mathrm{kS} / \mathrm{s}$ equivalent sample rate ensures an accurate $\mathrm{I}-\mathrm{V}$ curve is obtained [38]. The embedded system has a $1 \mathrm{MS} / \mathrm{s}$ sampling rate, the cut-off frequency selected was considered appropriate for the filters. The calculations conducted to select the appropriate filters were done according to the equations presented in the data sheet [39].

In addition, to enable the measurement of the cell temperature through a four-wire PT100, a constant-current source was implemented. This source was built from a reference signal generated by a CI mAX6350 (Maxim Integrated, San Jose, CA, USA), an operational amplifier LM358 (Texas Instruments Incorporated, Dallas, TX, USA) and a $1 \mathrm{k} \Omega$ resistor. This is shown in Figure 7.

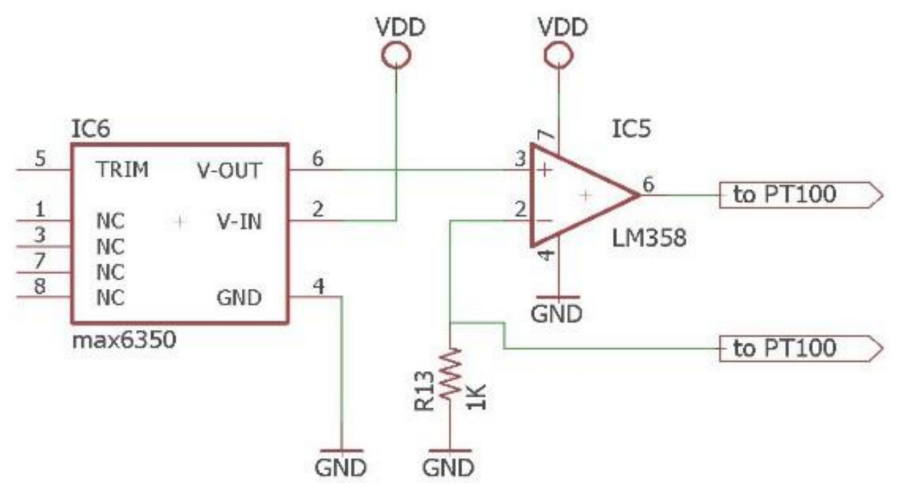

Figure 7. Constant-current source employed to enable the four-wire measurement of the PT100 sensor.

If only a PT100 temperature sensor is used, a constant-current source of $1 \mathrm{~mA}$ is recommended to avoid possible self-heating. This can be done by changing R13 to $5 \mathrm{k} \Omega$ (Figure 7 ). In order to avoid interferences between the conditioning stage and the power stage, the system was designed with optocouplers and an independent symmetrical source of $\pm 5 \mathrm{~V}$. The power stage is employed to control the process of precharge, charge and discharge of the capacitor. Its electrical schematic is shown in Figure 8. 


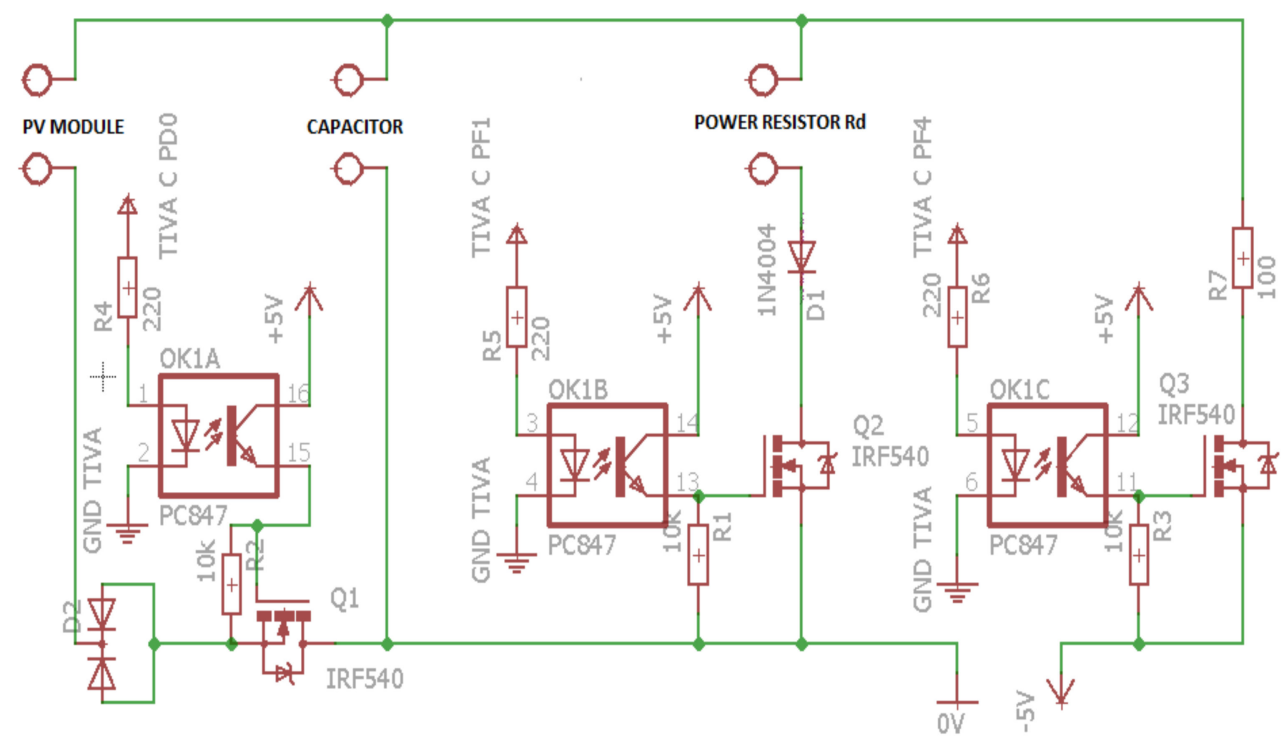

Figure 8. Power stage and symmetrical source for its supply.

\subsection{Instrument Cost}

One of the objectives of this project is the possibility of transferring the developed system to academic institutions interested in its implementation. This transference was also done through the publication of all the details of the project on a website (http://www.ger-unne.com.ar/IVtracer/IVtracer. zip) or in a repository (https://doi.org/10.5281/zenodo.3959804). All the hardware and software are open and free. In this sense, the final budget of mAterials involved in the system is relevant. The mAterial costs are presented in Table 3. The associated cost of the fabrication, mounting, calibration and setup were ignored. It is expected that the academic institutions will involve their staff and students regarding performing the activities related to the implementation of the system. Figure 9 shows the prototype version used for the experimental campaign.

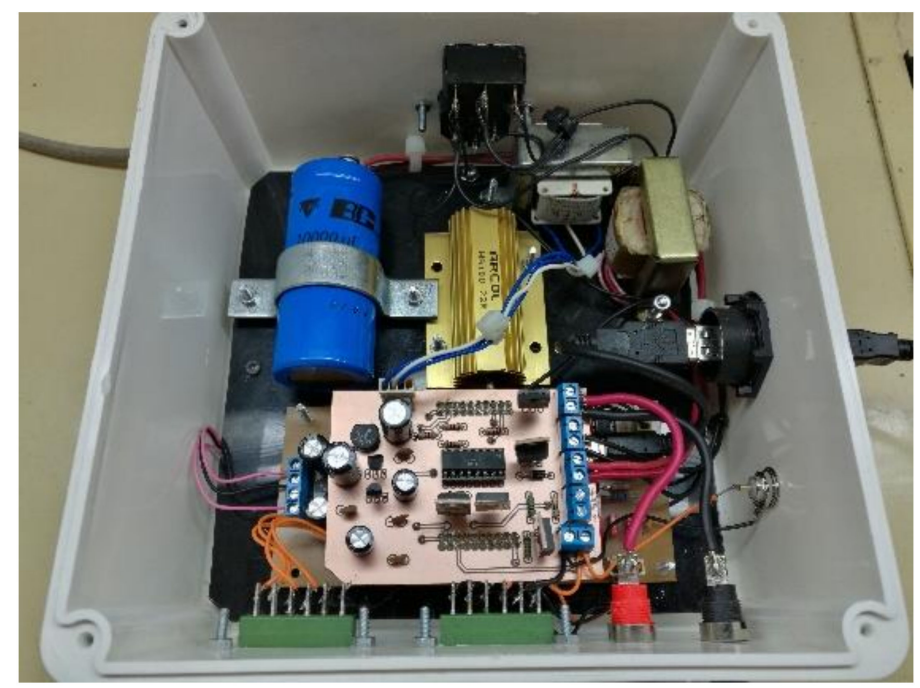

Figure 9. Prototype version used for the developed experimental campaign. 
Table 3. Partial costs and total cost of the mAterials and components associated to the project.

\begin{tabular}{cc}
\hline System Stage & Price \\
\hline Analog Signal Processing & $75.00 €$ \\
Power Drive & $48.50 €$ \\
Embedded System & $11.50 €$ \\
Miscellaneous & $28.00 €$ \\
Total Project Price & $163.00 €$ \\
\hline
\end{tabular}

\subsection{Instrument Calibration}

The developed instrument was subjected to a calibration process at the University of Jaén, southern Spain. This calibration consisted of the acquisition of discrete values applied by a power supply or voltage reference device, which was compared with a calibrated instrument considered as the reference. The reference signal was generated using a process signal calibrator C.A.1631 from Chauvin Arnoux (Reux, Normandie, France). This instrument has a resolution of $0.01 \mathrm{mV}$ in the range of $100 \mathrm{mV}$ and 1 $\mathrm{mV}$ in the range of $20 \mathrm{~V}$. The uncertainty given by the mAnufacturer is $0.02 \%$. In this case, the reference measurement system employed was a Keysight multimeter 34465A (Santa Rosa, CA, USA). The process was carried out throughout the complete operating range established for each measurement channel. Then, the calibration equations were obtained using a linear fit.

\section{Methodology of the Experimental Campaign}

In this section, the methodology used to estimate the error of the developed instrument is explained. This methodology was carried out in the laboratories that collaborated in this work: The Research and Development in Solar Energy (IDEA) research group of the University of Jaén (Spain); The Renewable Energy Group (GER) of the National University of the Northeast (Argentina); the Solar Energy Laboratory (LABSOL) of the Federal University of Rio Grande do Sul (Brazil); and the Centre for Energy, Environmental and Technological Research (CIEMAT) (Spain).

\subsection{Experimental Setup}

The developed instrument was connected in parallel with other measurement systems used as references during the I-V curve tracing. In Table 4, the measurement system used in each laboratory is shown.

Table 4. Reference system used in each laboratory.

\begin{tabular}{cc}
\hline Laboratory & Reference Instrument \\
\hline IDEA & Keysight 34465A (Santa Rosa, CA, USA) \\
GER & Keysight 34410A (Santa Rosa, CA, USA) \\
CIEMAT & Yokogawa WT3000 (Musashino, Tokyo, Japan) \\
LABSOL & Agilent 3458A (Santa Clara, CA, USA) \\
\hline
\end{tabular}

IDEA: The Research and Development in Solar Energy research group of the University of Jaén (Spain); GER: The Renewable Energy Group of the National University of the Northeast (Argentina); LABSOL: The Solar Energy Laboratory of the Federal University of Rio Grande do Sul (Brazil); CIEMAT: The Centre for Energy, Environmental and Technological Research (Spain).

The developed system produces a trigger signal in order to synchronise both the developed and reference systems. For the IDEA [28] and GER laboratories, the measurements were configured to obtain the voltage and current values with the same sampling rate on both systems. Consequently, the measured values were obtained simultaneously. Because the voltage and current samples of both pieces of equipment were equitemporal, point-by-point comparison of the measurements could be done. On the other hand, the CIEMAT and LABSOL laboratories collected the voltage and current using different time bases. Therefore, in this case, the comparison was only done for the mAin characteristic I-V points. 
For a more robust analysis, commercial PV modules of three different technologies were used at the IDEA laboratory: monocrystalline silicon, polycrystalline silicon and thin film. Table 5 presents the electrical characteristics of each module under standard test conditions (STC): $1000 \mathrm{~W} / \mathrm{m}^{2}$ irradiance, $25^{\circ} \mathrm{C}$ cell temperature and AM1.5 G spectral distribution. Those electrical characteristics were certified by the CIEMAT.

Table 5. Electrical characteristics of the modules under standard test conditions (STC) as certified by CIEMAT.

\begin{tabular}{cccccc}
\hline PV Technology & $\boldsymbol{P m}(\mathbf{W})$ & $\boldsymbol{V o c}(\mathrm{V})$ & $\boldsymbol{I s c}(\mathbf{A})$ & $\boldsymbol{V m}(\mathbf{V})$ & $\operatorname{Im}(\mathbf{A})$ \\
\hline Thin-Film $(120 \mathrm{Wp})$ & 112.7 & 59 & 3.09 & 41.9 & 2.69 \\
Poly-Si (160 Wp) & 165.4 & 43.61 & 5.03 & 34.8 & 4.75 \\
Mono-Si (245 Wp) & 243.4 & 37.44 & 8.74 & 30.2 & 8.07 \\
\hline
\end{tabular}

The thin-film module was tested using a $2200 \mu \mathrm{F} / 100 \mathrm{~V}$ electrolytic capacitor, the polycrystalline module was tested with a $3300 \mu \mathrm{F} / 100 \mathrm{~V}$ electrolytic capacitor and the monocrystalline module was tested with a 10,000 $\mu \mathrm{F} / 100 \mathrm{~V}$ electrolytic capacitor. These capacitors were calculated by considering Equation (1), for the lower Isc level expected, fixed sweeping time of $100 \mathrm{~ms}$ (worst-case scenario), and $5 \mathrm{kS} / \mathrm{s}$ sample rate to obtain 500 pairs of I-V points.

\subsection{Error Estimation}

In order to estimate the error produced by each channel (voltage and current), the absolute error for each of the $\mathrm{N}$ data pairs was obtained by using Equation (2). It was calculated using the difference between the measured value by the developed system and the value provided by the reference system under consideration:

$$
E a(n)=|X m(n)-X p(n)|,
$$

where:

$E a(n)$-absolute error at time instant $n$.

$X m(n)$ - voltage or current value measured by the developed instrument at time instant $n$.

$X p(n)$-voltage or current value measured by the reference instrument at time instant $n$.

Depending on the number of samples and the electrical characteristics of the PV device, a set of absolute error values was obtained for different operating ranges of the scale. As expected, the channel presented different errors depending on the measurement range. Therefore, the absolute error values obtained were different depending on the measurement ranges. However, this error distribution is inherent to the acquisition process of the I-V curve and must be taken into account to quantify the deviation between the measured and real curves.

The error can be analysed using statistical tools, where a representative value can be obtained as a mean value with the standard deviation value of the distribution. In this way, the sum of the mean value mentioned and the standard deviation becomes the mean error for each channel, as expressed in Equation (3). Furthermore, in order to normalise this value, it can be divided by the full-scale (FS) value of each channel (Equation (4)). In the case of the developed system, the FS value of the current value was $12 \mathrm{~A}$ and the FS value of the voltage was $100 \mathrm{~V}$.

$$
E a r=|\overline{E a}|+|\sigma|
$$

where:

Ear-representative absolute error.

$\overline{E a}-$ mean value of the error distribution.

$\sigma$-standard deviation of the error distribution.

$$
E \%=\frac{E a r \times 100}{\mathrm{FS}}
$$


where:

$E \%$-normalized percentage error.

FS-full-scale value.

Both the voltage and current are involved in the measurement of the I-V curve. The multiplication of these values represents the power of the PV module. As proposed in the data sheet [39], to estimate the error committed by the instrument on the acquisition of the power [40], the sum of the normalised percentage error of each channel was done by using Equation (5):

$$
E_{P} \%=E_{V} \%+E_{I} \%
$$

where:

$E_{P} \%$ - percentage error in the acquisition of the power.

$E_{V} \%$-percentage error in the voltage channel.

$E_{I} \%$-percentage error in the current channel.

In this way, it is possible to obtain a unique value that represents the error of the acquisition of the I-V curve.

\section{Results}

In this section, first, the results obtained from the experimental campaign carried out at the IDEA laboratories are presented. This data set represents the experimental campaign that involved the largest number of PV technologies and in which the I-V curves were measured at the same sampling rate. More than 50 curves were obtained for each PV module. In all the performed tests, the mAximum solar irradiance uncertainty provided by the sensor was $2.0 \%$ and the mAximum relative difference obtained between the reference system and the prototype was lower than $0.5 \%$.

The results include the power percentage error $\left(E_{P} \%\right)$, the percentage error in the voltage channel $\left(E_{V} \%\right)$ and the percentage error in the current channel $\left(E_{I} \%\right)$. These mAgnitudes were evaluated as a function of the irradiance since this was the most relevant parameter for defining the output of the PV technology.

The variations of the errors for the curves of the thin-film technology are presented in Figure 10. As can be seen, the values remained below $1 \%$ for irradiances between 550 and $1000 \mathrm{~W} / \mathrm{m}^{2}$. The voltage channel was the most influenced by the error. The values stayed practically constant independent of the values of the irradiance. Nevertheless, the error committed by the current channel slightly increased with irradiance, but it was lower in comparison with the voltage channel. This increment could be explained by the current value. High irradiances produced higher currents in the PV modules. This caused a lower charging time for the capacitor. In the tests, the sampling rate was fixed to a mean value, producing a constant measuring time. For higher irradiance values, the I-V sweep time decreased and an accumulation of data points near the Voc was produced. The percentage error of the current channel for the Voc point tended to increase due to an offset value in the developed instrument versus the null offset value of the reference system.

The percentage error values obtained for the polycrystalline silicon PV module are presented in Figure 11. The mAximum error was obtained for an irradiance equal to $1000 \mathrm{~W} / \mathrm{m}^{2}$ with a value of $1.37 \%$. Again, the error of the voltage remained constant and the current error increased with irradiance. In this case, the increment of the current error was higher in comparison with the thin-film module. The error produced in the voltage was lower than that produced in the current channel. This can be explained by considering the higher Isc value of this module in comparison with the previous case (see Table 5). 


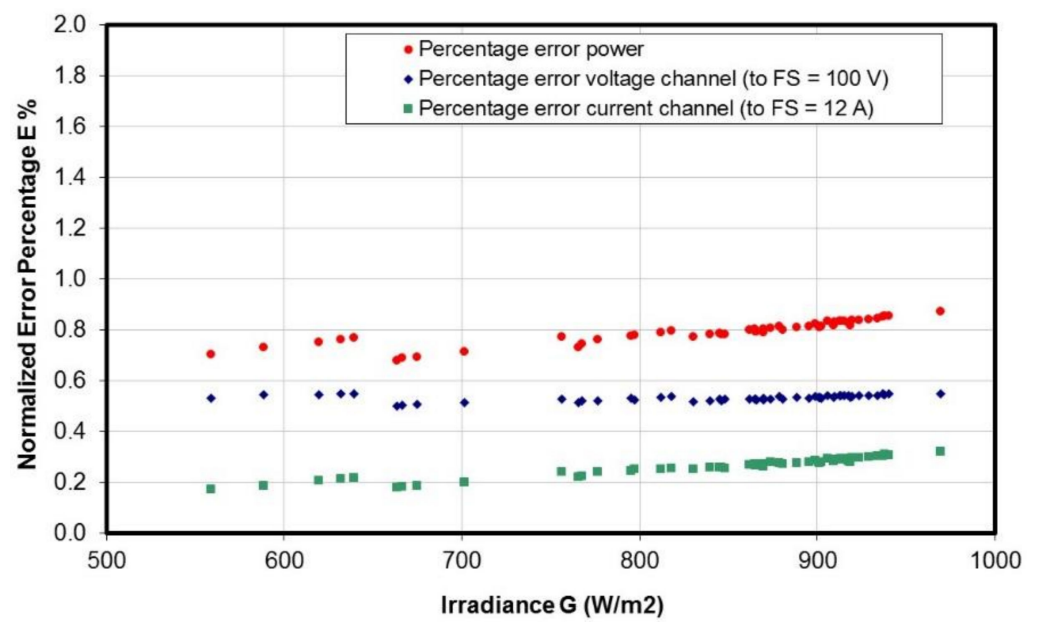

Figure 10. Variation of the percentage error of the power, the voltage channel and the current channel for the thin-film PV module.

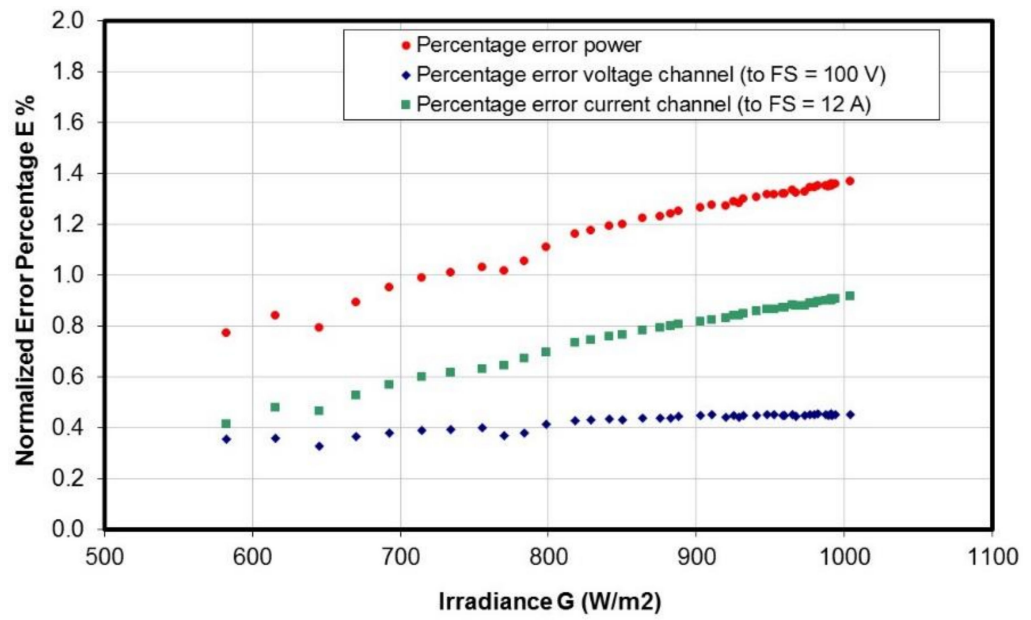

Figure 11. Variation of the percentage error of the power, the voltage channel and the current channel for the polycrystalline silicon PV module.

The trends of the percentage errors commented above were also repeated for the case of the monocrystalline silicon module. This is shown in Figure 12. This module presented a higher error value for the current channel, resulting in a power error equal to $1.58 \%$ at a $970 \mathrm{~W} / \mathrm{m}^{2}$ irradiance. This was the highest error obtained in this channel among all the PV technologies investigated. As also previously commented, this can be understood by considering that this module presents the highest Isc value among all the PV modules considered, see Table 5.

The variation of the error in the current channel above can be explained by the fixed sampling rate of the test conditions. This can be decreased by adapting the measurement times to the PV module connected and to the irradiance value. This adjustment can be done in two different ways: by adapting the sampling rate to the measurement time or by changing the capacitor.

As presented in Table 1, the embedded system allowed for a mAximum sampling rate of $1 \mathrm{MS} / \mathrm{s}$ to be achieved. This value was much higher than the value selected for the tests, which was approximately $5 \mathrm{kS} / \mathrm{s}$. By modifying the control software, an appropriate sampling rate can be estimated in order to avoid the sample accumulation at the Voc point.

In order to present a graphical comparison of the I-V curves obtained by both the developed and the reference systems, Figures 13-15 are shown. The curves were taken for irradiances close to $900 \mathrm{~W} / \mathrm{m}^{2}$. In the figures, an almost perfect mAtch between the points taken by both systems can be 
seen. This visually shows the low error values obtained in the analysis, where the highest error was $1.6 \%$.

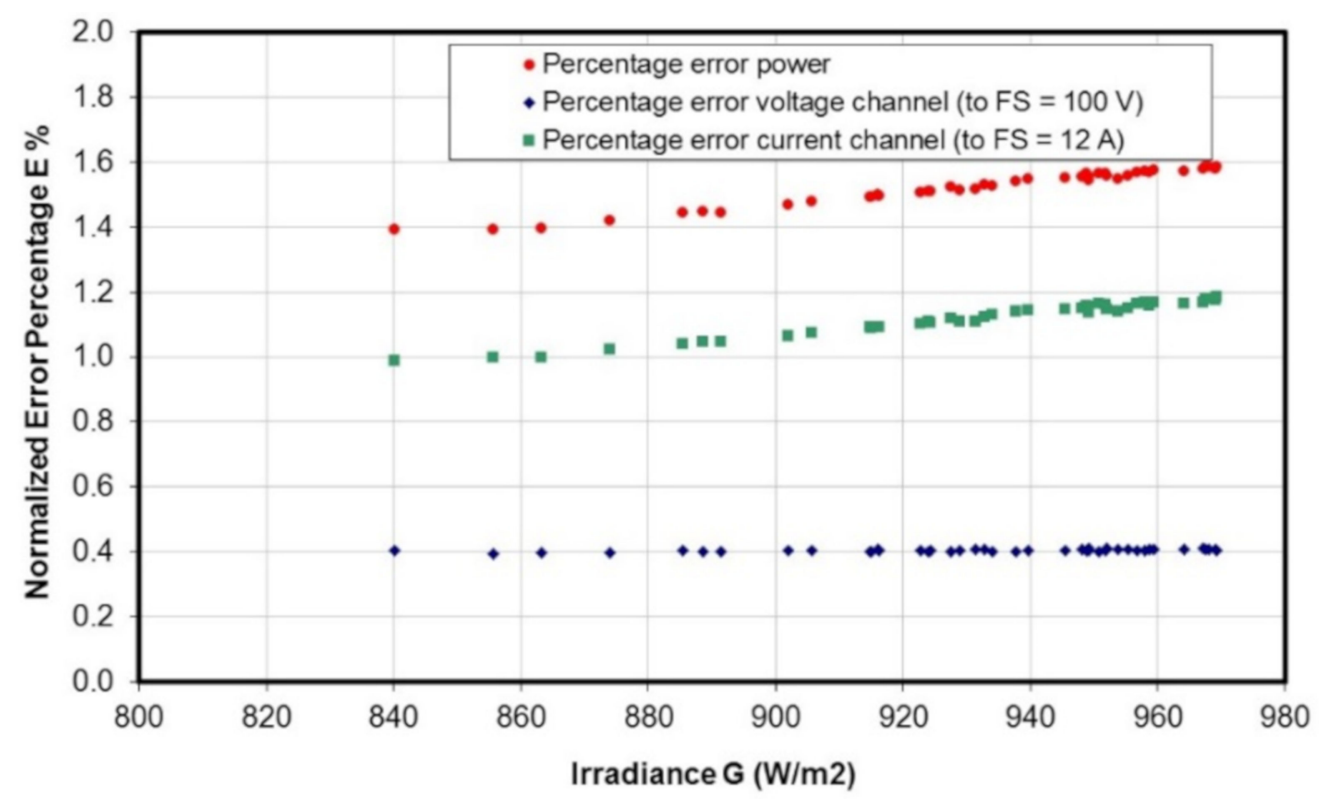

Figure 12. Variation of the percentage error of the power, the voltage channel and the current channel for the monocrystalline silicon PV module.

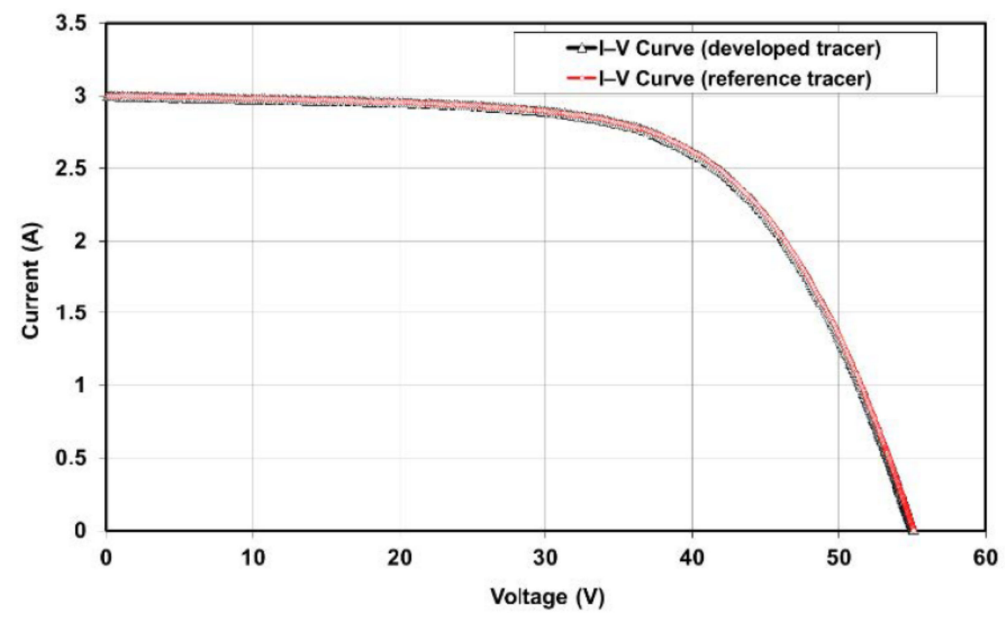

Figure 13. I-V curves obtained simultaneously between the developed tracer and the reference tracer for the thin-film PV module.

The tests above were repeated in the four different laboratories of the institutions previously mentioned. The results obtained by the IDEA and GER laboratories are summarized in Table 6 . The results obtained at the GER laboratory were analogous to the obtained at for the IDEA laboratory previously discussed. The voltage error was similar and the current error increased for higher current or irradiance values. The mAximum error values for the voltage, current and power were $0.08 \%, 0.78 \%$ and $0.85 \%$, respectively. On the other hand, the minimum error values were $0.04 \%, 0.67 \%$ and $0.72 \%$ for the voltage, current and power, respectively. 


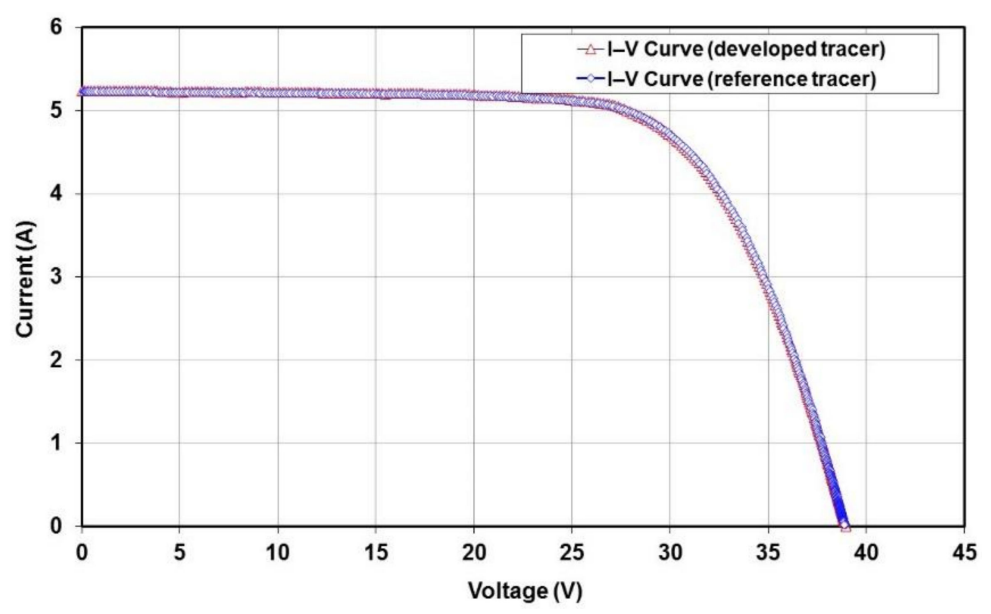

Figure 14. I-V curves obtained simultaneously between the developed tracer and the reference tracer for the polycrystalline silicon PV module.

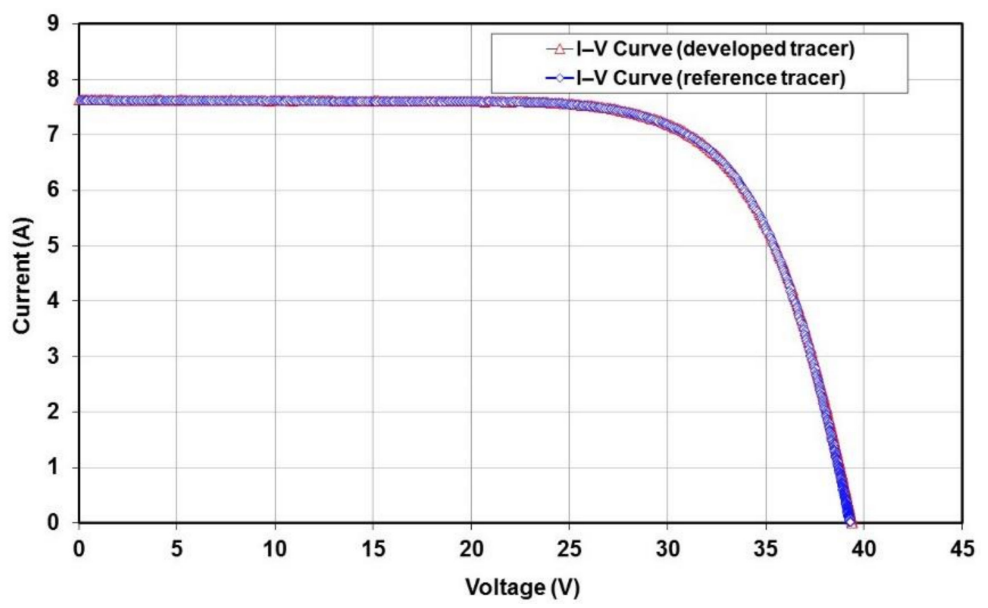

Figure 15. I-V curves obtained simultaneously between the developed tracer and the reference tracer for the monocrystalline silicon PV module.

Table 6. Summary of mAximum errors tested in the GER and IDEA laboratories.

\begin{tabular}{ccccc}
\hline PV Technology & Laboratory & $\boldsymbol{E}_{\boldsymbol{V}} \%$ & $\boldsymbol{E}_{\boldsymbol{I}} \boldsymbol{\%}$ & $\boldsymbol{E}_{\boldsymbol{P}} \boldsymbol{}$ \\
\hline Thin-Film $(120 \mathrm{Wp})$ & IDEA & 0.55 & 0.32 & 0.87 \\
Poly-Si $(160 \mathrm{Wp})$ & IDEA & 0.45 & 0.92 & 1.37 \\
Mono-Si $(245 \mathrm{Wp})$ & IDEA & 0.40 & 1.18 & 1.58 \\
Poly-Si $(50 \mathrm{Wp})$ & GER & 0.11 & 0.26 & 0.37 \\
Poly-Si $(140 \mathrm{Wp})$ & GER & 0.1 & 0.8 & 0.9 \\
\hline
\end{tabular}

The photovoltaic solar energy laboratory of CIEMAT was the reference institution of Spain in terms of the calibration and certification of any instrument related to this technology. The reference instrument used for the test of this work had a certified precision of $0.05 \%$ in the measurement. The test carried out at this institution was done for $30 \mathrm{I}-\mathrm{V}$ curves, obtaining mAximum errors of $1.50 \%$ for the current channel, $0.65 \%$ for the voltage channel and $2.13 \%$ for the power. On the other hand, the minimum error values were $0.02 \%, 0.01 \%$ and $0.2 \%$, respectively. The average deviation obtained for the Isc, Voc and Pm were $-0.1 \%,-0.4 \%$ and $+0.35 \%$, respectively. The uncertainties were \pm 0.02 A for the $I s c, \pm 0.2 \mathrm{~V}$ for the $V o c$ and $\pm 2 \mathrm{~W}$ for the $P m$. All the values given by CIEMAT included the deviations and uncertainties produced by the instant irradiance variations during the measurements and the errors on the estimation of the parameters. The LABSOL certification was in agreement with 
these results and showed similar error ranges. The results showed an average deviation of $0.58 \%$, $0.23 \%$ and $0.05 \%$ in the estimation of the $I s c, V o c$ and $P m$, respectively.

\section{Conclusions}

An I-V tracer for testing PV modules under real operating conditions was developed and presented. The equipment had a high degree of accuracy at a very low cost and a budget lower than $170 €$. Four institutions were involved in the experimental campaign conducted to check the quality of the new device. Three PV modules from different technologies (monocrystalline silicon, polycrystalline silicon and thin-film) were tested. The obtained statistical error of the acquisition of the I-V curve was found to be lower than $1.6 \%$ when compared to commercial instruments. This error could be lowered in future work by modifying the control software to adapt the sampling rate as a function of the PV module characteristics and the irradiance and temperature test conditions. The CIEMAT laboratory had certified average deviations lower than $0.4 \%$. The system can be implemented without the need for expensive instruments, ensuring access to the technology for the purpose of learning PV technology. All the source files to replicate the prototype presented in this work can be obtained at the following links: http://www.ger-unne.com.ar/IVtracer/IVtracer.zip or https://doi.org/10.5281/zenodo.3959804.

Author Contributions: All authors have contributed actively to the work that has resulted in this paper. M.C., A.F. and J.M.-R. wrote the paper. M.C. and J.M.-R. built and tested the prototype. J.M.-R. and A.R.G.M. performed the experiments. M.C., A.F. and J.d.l.C.H. conceived the idea and design of the device. J.d.l.C.H. and E.F.F. suggested and revised the scientific procedure. J.d.l.C.H, E.F.F. and L.H.V. revised the paper and provided suggestions regarding the implementation and validation of the electronic device. All authors have read and agreed to the published version of the manuscript.

Funding: This work has been supported by the Andalusian International Cooperation Agency (Agencia Andaluza de Cooperación Internacional para el Desarrollo (AACID)) in the framework of the project: "Emergiendo con el sol. Apoyo institucional al centro de energías renovables de la Universidad Nacional de Ingeniería en el campo de la generación de energía eléctrica empleando tecnología fotovoltaica" (Emerging with the sun. Institutional support to the renewable energy center of the National University of Engineering in the field of electricity generation using photovoltaic technology) and "Plan Plurianual de I+D" (Pluriannual R\&D Plan) from "Centro de Estudios Avanzados en Energía y Medio Ambiente" (Centre of Advanced Studies in Energy and Environment) of the University of Jaen in the framework of the project: "Acciones de cooperación al desarrollo en el mArco de la transferencia del conocimiento a universidades iberoamericanas. Caso de estudio: caracterización a sol real de módulos FV utilizando equipamiento de bajo coste" (Development cooperation actions in the framework of knowledge transfer to Ibero-American universities. Study case: real sun characterization of PV modules using low-cost equipment).

Acknowledgments: The authors would like to thank the laboratory staff from the LABSOL laboratory in Brazil and the CIEMAT staff in Spain for their collaboration in the experiments carried out in the project presented in this article.

Conflicts of Interest: The authors declare no conflict of interest.

\section{References}

1. Ellabban, O.; Abu-Rub, H.; Blaabjerg, F. Renewable energy resources: Current status, future prospects and their enabling technology. Renew. Sustain. Energy Rev. 2014, 39, 748-764. [CrossRef]

2. Alonso, M.; Amaris, H.; Alvarez-Ortega, C. Integration of renewable energy sources in smart grids by means of evolutionary optimization algorithms. Expert Syst. Appl. 2012, 39, 5513-5522. [CrossRef]

3. Bayod-Rújula, A.A. Future development of the electricity systems with distributed generation. Energy 2009, 34, 377-383. [CrossRef]

4. Adinolfi, G.; Graditi, G.; Siano, P.; Piccolo, A. Multiobjective Optimal Design of Photovoltaic Synchronous Boost Converters Assessing Efficiency, Reliability, and Cost Savings. IEEE Trans. Ind. Informatics 2015, 11, 1038-1048. [CrossRef]

5. Denholm, P.; mArgolis, R.M. Evaluating the limits of solar photovoltaics (PV) in traditional electric power systems. Energy Policy 2007, 35, 2852-2861. [CrossRef]

6. International Electrotechnical Commission. EN 61646:2008. Thin-Film Terrestrial Photovoltaic (PV) Modules-Design Qualification and Type Approval; International Electrotechnical Commission: Geneva, Switzerland, 2008. 
7. International Electrotechnical Commission. IEC 60904-1, Photovoltaic Devices, Part 1: Measurement of Photovoltaic Current-Voltage Characteristics; International Electrotechnical Commission: Geneva, Switzerland, 2006.

8. Muñoz, J.V.; Nofuentes, G.; Fuentes, M.; de la Casa, J.; Aguilera, J. DC energy yield prediction in large monocrystalline and polycrystalline PV plants: Time-domain integration of Osterwald's model. Energy 2016, 114, 951-960. [CrossRef]

9. Schuss, C.; Leppänen, K.; Remes, K.; Saarela, J.; Fabritius, T.; Eichberger, B.; Rahkonen, T. Detecting Defects in Photovoltaic Cells and Panels and Evaluating the Impact on Output Performances. IEEE Trans. Instrum. Meas. 2016, 65, 1108-1119. [CrossRef]

10. Almonacid, F.; Fernández, E.F.; mAllick, T.K.; Pérez-Higueras, P.J. High concentrator photovoltaic module simulation by neuronal networks using spectrally corrected direct normal irradiance and cell temperature. Energy 2015, 84, 336-343. [CrossRef]

11. Gasparin, F.P.; Bühler, A.J.; Rampinelli, G.A.; Krenzinger, A. Statistical analysis of I-V curve parameters from photovoltaic modules. Sol. Energy 2016, 131, 30-38. [CrossRef]

12. Montes-Romero, J.; Almonacid, F.; Theristis, M.; de la Casa, J.; Georghiou, G.E.; Fernández, E.F. Comparative analysis of parameter extraction techniques for the electrical characterization of multi-junction CPV and m-Si technologies. Sol. Energy 2018, 160, 275-288. [CrossRef]

13. Luque, A.; Hegedus, S. Handbook of Photovoltaic Science and Engineering; Wiley: Hoboken, NJ, USA, 2003; ISBN 0471491969.

14. Abbassi, A.; Gammoudi, R.; Dami, M.A.; Hasnaoui, O.; Jemli, M. An improved single-diode model parameters extraction at different operating conditions with a view to modeling a photovoltaic generator: A comparative study. Sol. Energy 2017, 155, 478-489. [CrossRef]

15. Ishaque, K.; Salam, Z.; Taheri, H. Simple, fast and accurate two-diode model for photovoltaic modules. Sol. Energy mAter. Sol. Cells 2011, 95, 586-594. [CrossRef]

16. Celik, A.N.; Acikgoz, N. Modelling and experimental verification of the operating current of mono-crystalline photovoltaic modules using four- and five-parameter models. Appl. Energy 2007, 84, 1-15. [CrossRef]

17. Attivissimo, F.; Di Nisio, A.; Savino, M.; Spadavecchia, M. Uncertainty analysis in photovoltaic cell parameter estimation. IEEE Trans. Instrum. Meas. 2012, 61, 1334-1342. [CrossRef]

18. Willoughby, A.A.; Osinowo, M.O. Development of an electronic load I-V curve tracer to investigate the impact of Harmattan aerosol loading on PV module pern2tkformance in southwest Nigeria. Sol. Energy 2018, 166, 171-180. [CrossRef]

19. Vega, A.; Valiño, V.; Conde, E.; Ramos, A.; Reina, P. Double sweep tracer for I-V curves characterization and continuous monitoring of photovoltaic facilities. Sol. Energy 2019, 190, 622-629. [CrossRef]

20. Sánchez-Pacheco, F.J.; Sotorrío-Ruiz, P.J.; Heredia-Larrubia, J.R.; Pérez-Hidalgo, F.; De Cardona, M.S. PLC-based PV plants smart monitoring system: Field measurements and uncertainty estimation. IEEE Trans. Instrum. Meas. 2014, 63, 2215-2222. [CrossRef]

21. Zhu, Y.; Xiao, W. A comprehensive review of topologies for photovoltaic I-V curve tracer. Sol. Energy 2020, 196, 346-357. [CrossRef]

22. Chen, Z.; Lin, W.; Wu, L.; Long, C.; Lin, P.; Cheng, S. A capacitor based fast I-V characteristics tester for photovoltaic arrays. Energy Procedia 2018, 145, 381-387. [CrossRef]

23. Amiry, H.; Benhmida, M.; Bendaoud, R.; Hajjaj, C.; Bounouar, S.; Yadir, S.; Raïs, K.; Sidki, M. Design and implementation of a photovoltaic I-V curve tracer: Solar modules characterization under real operating conditions. Energy Convers. mAnag. 2018, 169, 206-216. [CrossRef]

24. Leite, V.; Chenlo, F. An improved electronic circuit for tracing the IV characteristics of photovoltaic modules and strings. In Proceedings of the International Conference on Renewable Energies and Power Quality, Granada, Spain, 23-25 mArch 2010; Volume 1, pp. 1224-1228.

25. García-Valverde, R.; Chaouki-Almagro, S.; Corazza, M.; Espinosa, N.; Hösel, M.; Søndergaard, R.R.; Jørgensen, M.; Villarejo, J.A.; Krebs, F.C. Portable and wireless IV-curve tracer for $>5 \mathrm{kV}$ organic photovoltaic modules. Sol. Energy mAter. Sol. Cells 2016, 151, 60-65. [CrossRef]

26. Leite, V.; Batista, J.; Chenlo, F.; Afonso, J.L. Low-Cost I-V Tracer for Photovoltaic Modules and Strings. In Proceedings of the International Symposium on Power Electronics, Electrical Drives, Automation and Motion, Naples, Italy, 18-20 June 2014. 
27. Papageorgas, P.; Piromalis, D.; Valavanis, T.; Kambasis, S.; Iliopoulou, T.; Vokas, G. A low-cost and fast PV $\mathrm{I}-\mathrm{V}$ curve tracer based on an open source platform with M2M communication capabilities for preventive monitoring. Energy Procedia 2015, 74, 423-438. [CrossRef]

28. Montes-Romero, J.; Piliougine, M.; Muñoz, J.; Fernández, E.; de la Casa, J. Photovoltaic Device Performance Evaluation Using an Open-Hardware System and Standard Calibrated Laboratory Instruments. Energies 2017, 10, 1869. [CrossRef]

29. Spertino, F.; Ahmad, J.; Ciocia, A.; Di Leo, P.; Murtaza, A.F.; Chiaberge, M. Capacitor charging method for I-V curve tracer and MPPT in photovoltaic systems. Sol. Energy 2015, 119, 461-473. [CrossRef]

30. Blaesser, G.; Munro, D. Guidelines for the assessment of photovoltaic plants. In Document C: Initial and Periodic Test on Photovoltaic Plants; Europeean Commission Joint Research Centre: Ispra, Italy, 1995.

31. Duran, E.; Piliougine, M.; De Cardona, M.S.; Galan, J.; Andujar, J.M. Different methods to obtain the I-V curve of PV modules: A review. In Proceedings of the Conference Record of the IEEE Photovoltaic, San Diego, CA, USA, 11-16 mAy 2008.

32. Di Nisio, A.; Di Noia, T.; Carducci, C.G.C.; Spadavecchia, M. High dynamic range power consumption measurement in microcontroller-based applications. IEEE Trans. Instrum. Meas. 2016, 65, 1968-1976. [CrossRef]

33. Firman, A.; Zini, L.; Sanchez, R.; Vera, L. Desarrollo y calibración de dispositivos fotovoltaicos para determinar el recurso solar utilizable por sfcr. Av. Energías Renov. Medio Ambient. 2014, 18, 9-17.

34. Almonacid, F.; Rodrigo, P.; Fernández, E.F. Determination of the current-voltage characteristics of concentrator systems by using different adapted conventional techniques. Energy 2016, 101, 146-160. [CrossRef]

35. Salvadori, F.; Gehrke, C.S.; Hartmann, L.V.; mAcedo, E.T.; de Lima, A.L.; mAia, S.L. Design of an intelligent electronic device based on TivaC platform for smart grid applications. In Proceedings of the 2016 IEEE International Instrumentation and Measurement Technology Conference Proceedings, Taiwan, 23-26 mAy 2016; pp. 1-6.

36. Texas Instruments. Tiva TM4C123GH6PM Microcontroller Data Sheet; Texas Instruments Incorporated: Dallas, TX, USA, 2014.

37. Giordani, A.; mAri, L. Measurement, Models, and Uncertainty. IEEE Trans. Instrum. Meas. 2012, 61, 2144-2152. [CrossRef]

38. Martínez-Moreno, F.; Lorenzo, E.; Muñoz, J.; Moretón, R. On the testing of large PV arrays. Prog. Photovolt. Res. Appl. 2011, 15, 659-676. [CrossRef]

39. Kitchin, C.; Counts, L. Analog Devices Instrumentation Amplifier AD620; Analog Devices: Norwood, mA, USA, 2011.

40. Taylor, J.R. Introduction To Error Analysis: The Study of Uncertainties in Physical Measurements; ASMSU/Spartans.4.Spartans Textbook; University Science Books: Mill Valley, CA, USA, 1997; ISBN 9780935702750.

(C) 2020 by the authors. Licensee MDPI, Basel, Switzerland. This article is an open access article distributed under the terms and conditions of the Creative Commons Attribution (CC BY) license (http://creativecommons.org/licenses/by/4.0/). 